\title{
UTICAJ FILMSKE INDUSTRIJE NA TURISTIČKE DESTINACIJE
}

\section{Nataša Đorđević, Snežana Milićević}

Univerzitet u Kragujevcu, Fakultet za hotelijerstvo i turizam u Vrnjačkoj Banji, Vrnjačka Banja, Srbija
Correspondence:

Nataša Đorđević

e-mail:

natasa.djordjevic@kg.ac.rs

\section{Rezime:}

Kao rezultat promena u okruženju, na turističkom tržištu se javljaju specifični oblici turizma, kakav je i filmski turizam. Cilj rada je prikazati uticaje koje filmska industrija ima na turističke destinacije i na osnovu toga definisati šta sve obuhvata turistička destinacija filmskog turizma. Filmski turizam se na određenom prostoru može pojaviti kao rezultat prikazivanja te destinacije na filmu ili seriji, zbog snimanja na toj lokaciji, usled postojanja atraktivnosti vezanih za filmsku industriju kao što su zabavni parkovi, festivali i slično. Da bi se definisao uticaj filmske industrije na destinaciju treba ukazati na to da je destinaciju teško definisati i da njen prostor nije uvek definisan jasnim administrativnim granicama. Granice turističke destinacije najčešće su određene željama turista i zbog toga se moraju ispitati motivi putovanja u filmskom turizmu.

Ključne reči:

filmski turizam, film, turistička destinacija, filmski festivali, turisti

UVOD

Savremene tendencije na turističkom tržištu nameću brojne izazove sa kojima se menadžment destinacija sreće u svom poslovnom okruženju (Milićević, Đorđević, 2016). Promene u turizmu najčešće počinju sa promenama u željama i zahtevima turista. Zbog toga se javljaju različiti oblici turizma koji su fokusirani na određne tržišne niše, kako bi subjekti turističke ponude kreirali proizvod u skladu sa savremenim zahtevima tržišta.

Kulturni turizam je specifični oblik turizma koji beleži rast na turističkom tržištu. Kulturni turizam predstavlja putovanje turista u cilju upoznavanja sa kulturnim atrakcijama i aktivnostima izvan mesta svog boravka radi zadovoljenja kulturnih potreba (Milićević, Štetić, 2017). Kako Svetska turistička organizacija ističe oko $40 \%$ međunarodnog turističkog prometa u svetu čine turisti kulturnog turizma (UNWTO, 2018). Ovakva situacija se može posmatrati i iz ugla rasta popularnosti tržišnih niša koje ubrajamo u kulturni turizam, kao što je filmski turizam.

Usled povećanja mogućnosti međunarodnih putovanja i usled brzog razvoja industrije zabave, filmski turizam pokazuje svetsku tendenciju rasta. Film je mnogo više od običnog alata u promociji i marketingu destinacije, jer obuhvata i filmska studija i lokacije snimanja. Žanrovi 
su različiti, od blokbastera, kultnih tv serija i animacija, a pokrivaju se područja od centra Njujorka, do prašuma Amazona i pustinja Afrike. Turizam podstaknut filmovima može da oživi regionalne centre kao i turizam velikih gradova, ali i noseći sa sobom posebne probleme (zagađenje okoline, preveliki priliv posetilaca u manja mesta, itd.) (Isaković, 2016, str. 164).

Osnovna pretpostavka rada je da filmska industrija ostvaruje različite pozitivne uticaje na razvoj turizma u destinaciji. Najpre ova industrija može da utiče na imidž destinacije, da doprinese kreiranju dodatnih atraktivnosti u destinaciji i razvoju filmskog poslovnog turizma, što sve ukupno utiče na veću konkurentnost destinacije na turističkom tržištu.

\section{RAZVOJ FILMSKOG TURIZMA}

Filmski turizam je novi oblik turizma koji podrazumeva obilazak čuvenih mesta snimanja (Pivac, 2018), odnosno podrazumeva posetu turista nekoj destinaciji ili atrakciji koja rezultira kao posledica njenog pojavljivanja na televiziji ili bioskopskom platnu (Evans, 1997). Sa sigurnošću se ne može utvrditi kada je nastala želja za posetom određenih mesta koja je probuđena posredstvom određenog medija. Još su u 18. veku umetničke slike egzotičnih destinacija budile čuđenje i žudnju za obilaskom novih mesta.

Sa razvojem kinematografije počevši od 19. veka povećava se uloga koju film ima kao sredstvo za podsticanje putovanja. Zahvaljujući filmu Pobuna na brodu Bounti - Mutiny on the Bounty (1935) raste popularnost ostrva Tahiti u Pacifičkom okeanu. Kasnije su i filmovi: Treći čovek - The Third Man (1949), Nijagara - Niagara (1953), Drž'te lopova -To Catch a Thief (1955), Most na reci Kvaj-Bridge on the River Kwai (1958) i drugi podstakli mnoga turistička putovanja.

Filmski turizam se razvija zajedno sa masovnim turizmom 1970-ih i 1980-ih godina, kao i razvojem produkcijskih kuća i skupih blokbaster hitova (Roesch, 2009). Značajniji interes filmskog turizma u Evropi i Svetu javlja se nakon filma Gospodar prstenova - The Lord of the Rings (2001), kada je broj turista u Novom Zelandu, gde je film sniman, povećan za 40\%, a destinacija dobila imidž prestonice fantazije o Srednjoj zemlji (SEEBTM, 2018). Mnogo je primera koji svedoče o tome da nakon filmske premijere, dolazi do povećanja broja turista u destinacijama u kojima su snimani upečatljvi filmski kadrovi (tabela 1 ).

Tabela 1. Uticaj filma na povećanje broja turista

\begin{tabular}{|c|c|c|}
\hline Film & Lokacija & Posećenost \\
\hline Hrabro srce & Škotska & broj turista veći za 300\% \\
\hline Ples sa Vukovima & Fort Hayes, Kanzas & porast posete od $25 \%$ \\
\hline Polje snova & Ajova & porast posete od $35 \%$ \\
\hline Gospodar prstenova & Novi Zeland & porast turista iz UK za $10 \%$ na godišnjem nivou \\
\hline Hari Poter & $\begin{array}{l}\text { više lokacija u Ujedinjenom } \\
\text { Kraljevstvu }\end{array}$ & porast posete od $50 \%$ \\
\hline Krokodil Dandi & Australija & porast američkih turista za oko $20,5 \%$ \\
\hline Plaža & Tajland & porast mlađih turista za oko $22 \%$ u 2000 . godini \\
\hline Nemoguća misija 2 & Nacionalni park, Sidnej & porast posete $200 \%$ u 2000 . godini \\
\hline Četiri venčanja i sahrana & $\begin{array}{l}\text { The Crown Hotel, } \\
\text { Ujedinjeno Kraljevstvo }\end{array}$ & velika popunjenost hotela iz godine u godinu \\
\hline Spasavanje redova Rajana & Normandija, Francuska & porast posete američkih turista za oko $40 \%$ \\
\hline Gordost i predrasude & Lyme Park, UK & porast posete za $150 \%$ \\
\hline Troja & Čanakle, Turska & povećanje broja turista za $73 \%$ \\
\hline Mandolina kapetana Korelija & Kefalonija, Grčka & povećanje broja turista za $50 \%$ \\
\hline
\end{tabular}

Izvor: Hudson, S., \& Ritchie, J. R. B. (2006). Promoting Destinations via Film Tourism: An Empirical Identification of Supporting Marketing Initiatives. Journal of Travel Research, 44(4), 387-396. 
Filmski turizam može biti (Tanskanen, 2012):

- Filmski turizam na lokaciji je oblik turizma koji podrazumeva obilazak lokacija gde je sniman film ili lokacija koje su povezane sa određenim filmom. Nije isključeno da na tim lokacijama ostane filmski set, koji turisti mogu da obiđu;

- Filmski turizam van lokacije, odnosno turizam koji podrazumeva posetu "veštačkih" lokacija izgrađenih za snimanje ili za turističke svrhe. Danas gotovo svaki veći filmski studio, kao što su Warner Bros, Universal i Fox nudi studio filmske ture, gde posetioci mogu da se upoznaju sa načinom stvaranja filma, i poseduju tematske filmske parkove kao što je Universal Studio na Floridi u kojem se mogu videti atraktivnosti vezane za filmove Terminator - Terminator, E.T. vanzemaljac - E.T. the Extra-Terrestrial, Zvezdane staze - Star Trek i druge. U ovu vrstu turizma ubrajaju se posete filmskim premijerama i filmskim festivalima.

- Filmski turizam kao poslovni turizam odnosi se na to da filmski stvaraoci odnosno producenti, koji traže pogodne lokacije gde će snimati film ili već snimaju film na određenoj lokaciji, mogu se posmatrati kao poslovni turisti. Turističke agencije bi trebalo da obrate pažnju na ovakav tip poslovnih turista, zbog toga što ostvaruju veći broj noćenja od drugih poslovnih turista.

Motivacija u filmskom turizmu predstavlja kombinaciju povećanog interesa za film i samoaktuelizaciju, u tom smislu razlikujemo (Macionis, 2004):

- slučajnog filmskog turistu čiji je primarni motiv socijalna interakcija i novitet; imaju saznanja da je lokacija usko vezana za film no ne pokazuju interesovanja za to;

- generalnog filmskog turistu koji učestvuje u filmskim aktivnostima i kome je primarni motiv upoznavanje novog, edukacija i nostalgija;

- specifičnog filmskog turistu koji aktivno posećuje destinaciju tražeći lokacije viđene na filmu i čiji motivi su nostalgija, romansa, fantazija, osobno preispitivanje i samoaktuelizacija, te mogu biti vođeni idejom hodočašća.

\section{TURISTIČKE DESTINACIJE FILMSKOG TURIZMA}

Kada govorimo o povezanosti filma sa turističkim destinacijama najpre imamo u vidu promociju, jer $\mathrm{u}$ svrhu promovisanja turističke ponude destinacije koriste se različite forme filmova, kao što su: promotivni turistički filmovi, dokumentarni filmovi i reportaže o destinaciji kao i igrani filmovi i serije u kojima se radnja odvija na određenoj destinaciji.

Sve je više destinacija koje se trude da privuku pažnju filmskih produkcijskih kuća, jer u slučaju da postanu lokacija snimanja filma mogu prosperirati pre svega zbog priliva novca po osnovu snimanja (naplata korišćenja lokacije, korišćenje hotela, restorana i ostalih sadržaja destinacijske ponude od strane filmske ekipe i drugo) ali i po osnovu kreiranja pozitivnog imidža nakon emitovanja filma ili serije. Češka je sredinom devedesetih godina filmovima poput Nemoguće misije - Mission Impossible počela da koristi šanse koje proizilaze iz pozitivnog uticaja filmske industrije na turizam. Nakon Češke i mnoge druge zemlje istočne Evrope, među kojima je i Rumunija, Bugarska, Mađarska, Slovačka, okreću se ka tome da svoju državu, ali i područje Istočne Evrope predstave kao atraktivnu destinaciju za snimanje filmova i serija i time dobiju pažnju takozvanih američkih Runaway produkcija (SEEBTM, 2018). Glavnu ulogu u promovisanju destinacije kao pogodno mesto za snimanje filmova i serija mogu imati destinacijske menadžment organizacije (Destination management organization - DMO). Dobar primer za to su DMO Britanije, SAD-a i Singapura. Organizacija Visit Britain kako bi se generisala ekonomska korist za turističku delatnost, ima za cilj da Veliku Britaniju predstavi kao destinaciju pogodnu za snimanje indijskih filmova (Bollywood films) (Tanasić, 2015, str.492).

U Srbiji je formirana Srpska filmska asocijacija - Serbia Film Commission, čiji je fokus ekonomski razvoj u području filmske industrije, kojim se podstiče i privlače inostrane filmske produkcije koje koriste srpske lokacije, usluge, opremu i ekipe, čime će se stvoriti radna mesta u Srbiji i generisati prihod za firme registrovane u Srbiji (SEEBTM, 2018). Kako Srpska filmska asocijacija ističe, direktni ekonomske efekti bi bili (Božanić, 2018): 
- Zapošljavanje velikog broja filmskih radnika, od visoko plaćenih poslova do nekvalifikovanih radnika (150-1500 po projektu);

- Razvoj malih i srednjih preduzeća;

- Generisanje direktnih prihoda javnom sektoru kroz izdavanje dozvola;

- Direktno strano/devizno ulaganje u kratkom roku - pasivni izvoz usluga;

- Podizanje nivoa kvaliteta domaće filmske produkcije i radnika;

- Upošljavanje radne snage i u sektorima izvan filmske industrije (turistička infrastruktura, transport, bankarski sektor, drvna i tekstilna industrija, zanatlije, telekomunikacije, itd.

Da li će destinacija postati lokacija za snimanje zavisi od produkcije ili umetničkog dela filmske ekipe, koji odlučuju na osnovu toga da li destinacija odgovara unapred postavljenim zahtevima filmske radnje. Takođe, njihova odluka o ovome se može bazirati i na marketinškim strategijama. Bez obzira na to kako destinacija postaje lokacija snimanja filma, gotovo je izvesno da nakon njenog prikazivanja na filmu ona može postati još atraktivnija (Pavković, Filipović, Vlastelica-Bakić, 2015, str. 80).

Pored ovoga Beeton (2005) navodi još i sledeće oblike uticaja filma na turističke destinacije:

- primarnu motivaciju turista da posete određenu destinaciju može predstavljati film, destinaciju ili lokaciju na kojoj je sniman film turista posećuje tokom dužeg odmora na kojem se nalazi.

- turistima su atraktivne lokacije gde žive filmske zvezde,

- turisti posećuju destinaciju koja je povezana sa filmom usled nostalgije, jer ih radnja filma asocira na neka prošla vremena.

- razlog da turisti posete određenu destinaciju ili lokaciju na kojoj je sniman film može biti i želja da odaju počast filmu (tzv. filmsko hodočašće),

- nakon snimanja filma kreiraju se atrakcije u vezi sa njim sa ciljem privlačenja turista, te turisti iz ovog razloga posećuju destinaciju, kao i da bi konzumirali tzv. filmske ture,

- tokom ili nakon snimanja filma, turisti posećuju destinaciju kako bi obišli filmske studije,

- iako je film sniman na drugoj lokaciji, turisti posećuju i destinaciju gde se odigrava filmska radnja (npr. film Hrabro srce - Brave Hearth je privukao veliki broj turista u Škotsku iako je većina scena snimana u Irskoj),

- turisti posećuju filmske festivale i sl.

Destinacije filmskog turizma poseduju jednu ili više atrakcija povezane sa određenim filmom koje mogu biti realne lokacije, prerušena mesta, izmišljene lokacije (Božanić, 2018). Ovome svakako treba dodati i filmske manifestacije koje turisti posećuju.

\section{PRIMERI ATRAKTIVNIH FILMSKIH TURISTIČKIH DESTINACIJA}

Filmske industrije filmom, kao svojim jedinstvenim proizvodom mogu uticati da više destinacija istovremeno postanu popularne među turistima. Primer za to je biografski film o Ernestu Če Gevari, Dnevnik motocikliste - Diarios de motocicleta, u kojem je prikazano motociklističko putovanje Južnom Amerikom sa njegovim prijateljem. Na putovanju koji traje osam meseci, prijatelji putuju preko 14.000 kilometara, od Argentine preko Čilea, Perua i Kolumbije do Venecuele. Ubrzo nakon prikazivanja filma, pojedini turoperatori ponudili su paket aranžmane koji uključuju putovanje rutom kojom je veliki revolucionar sa svojim prijateljem prošao i koja je predstavljena u filmu (The Guardian, 2018). Ova ruta predstavlja specifičnu destinaciju filmskog turizma čija je atraktivnost kao jedinstvene celine bazirana na realnom istorijskom događajem, ali na čiju je popularizaciju najpre uticao film.

Kao što je već pomenuto, nakon snimanja filmova i serija dešava se i da čitav set ostane na određenoj lokaciji. Zbog ovoga je Tunis, pored svojih brojnih prirodnih i kulturnih atraktivnosti, danas poznat i kao mesto hodočašća za ljubitelje filmske sage Ratovi zvezda - Star Wars. Filmski set je izgrađen u stilu berberskih naselja i nalazi se u pustinji Sahara, u blizini grada Tozeura. Iako je u pustinji, ovde se mogu sresti trgovci koji prodaju suvenire, jer turisti posećuju ovu lokaciju i 40 godina nakon objavljivanja filma. Dugogodišnju atraktivnost ove destinacije treba povezati sa velikim uspehom i trajanjem popularnosti filmske sage Ratovi zvezda. 
Još jedna atraktivnost koja proističe iz filmske industrije su filmski festivali. Najprestižniji filmski festival je Festival u Kanu - Le Festival International du Film de Cannes. Osnovan je 1946. godine i održava se svake godine u maju mesecu. Kan je destinacija primorskog tipa, poznata i po letnjem i zimskom turizmu, kongresnom, festivalskom, ali zbog tipa ovog nadaleko poznatog festivala treba dodati i to da je u pitanju destinacija filmskog turizma.

Pored manifestacija, destinacije mogu da poseduju atrakcije koje su kreirane na osnovu filma. U Londonu je izgrađen veliki zabavni park baziran na filmovima o Hari Poteru - Harry Poter. Ovaj zabavni park se prostire na skoro $50.000 \mathrm{~m}^{2} \mathrm{i}$ u toku jednog dana ovaj park poseti i do 6.000 posetilaca. Da filmske turističke atraktivnosti doprinose povećanju ekonomske dobiti, govori i činjenica da je u 2016. godini ovaj zabavni park ostvario prihod od 126,6 miliona britanskih funti (Sylt, 2017).

\section{ZAKLJUČAK}

Sa razvojem tehnologije i kinematografije povećava se uloga koju filmska industrija ima u turizmu. Uticaj koji filmska industrija ostvaruje na imidž destinacije i na kreiranje atrakcija vezanih za film, može da rezultira porastom broja turista. Takođe, destinacija može profitirati direktno kada postane mesto snimanja određenog filma, čime se razvija filmski poslovni turizam. Možemo zaključiti da se uticaj filmske industrije na turističku destinaciju može podeliti na osnovu perioda delovanja na sledeći način: uticaj pre objavljivanja filma (period snimanja filma - filmski poslovni turizam), uticaj posle objavljivanja filma (motivisani gledaoci postaju turisti) i periodičan uticaj (održavanje različitih manifestacija).

Da bi jedno mesto postalo destinacija filmskog turizma mora posedovati komunikativne i receptivne faktore i da njegova atraktivnost bude povezana sa određenim filmom, odnosno njegovom proizvodnjom, njegovim elementima (priča, glumci i drugo), krajnjim proizvodom, njegovim izvedenim atrakcijama (realno ili fiktivno) i/ili sa filmskim događajem. Granice ovakvih destinacija utvrđene su motivima posete koji su u osnovi inicirani aktom filmske industrije. U tom smislu destinacija filmskog turizma može biti i ruta kao što je to slučaj rutom revolucionarnog lidera Če u Južnoj Americi.

Film se u turizmu može posmatrati kao sredstvo koje stimuliše potencijalne turiste da preduzmu određeno putovanje. Stoga, filmski turizam je turizam koji obuhvata ne samo posetu destinacijama koje se pojavljuju u filmu, već putovanje koje je motivisano filmom i koje uključuje doživljaj filmskih atraktivnosti. Ovim se uključuje poseta različitim destinacijama koje poseduju atraktivnosti vezane za određeni film ili filmove.

Važno je naglasiti da film i celokupna filmska industrija može uticati na imidž destinacije kako pozitivno, tako i negativno. Potrebna su dodatna istraživanja uticaja filmske industrije na turizam analizom pojedinačnih primera, jer ovaj specifični oblik turizam može kreirati pritisak na prirodu, lokalnu zajednicu i ekonomiju. Ovo se naročito odnosi na mala mesta koja zbog filmske industrije postaju atraktivna i gde povećan broj turista može da šteti okolini.

\section{ZAHVALNOST}

Rad predstavlja deo rezultata na projektu III 46006 "Održiva poljoprivreda i ruralni razvoj u funkciji ostvarivanja strateških ciljeva Republike Srbije u okviru dunavskog regiona”, finansiranog od strane Ministarstva prosvete, nauke i tehnološkog razvoja Republike Srbije

\section{LITERATURA}

Beeton, S. (2005). Film-induced Tourism. Clevdon, UK: Channel View Publications.

Božanić, M. (2014). Marketing destinacije kroz film. Preuzeto 17.08.2018: http://www.ekof.bg.ac.rs/wp-content/ uploads/2014/05/Film-kao-kanal-promocije.pdf

Evans, M. (1997). Plugging into TV tourism. English Tourist Board, 8(4), 302-332.

Isaković, S. (2016). Umetničke prakse u kontekstu kulturnog turizma. Vrnjačka Banja: Univerzitet u Kragujevcu, Fakultet za hotelijrstvo i turizam u Vrnjačkoj Banji. 
Macionis, N. (2004). Understanding the Film-Induced Tourist. In Frost, Warwick, Croy, Glen and Beeton, Sue (Eds.). International Tourism and Media Conference Proceedings. 24th-26th November 2004. Melbourne: Tourism Research Unit, Monash University.

Milićević, S., Đorđević, N. (2016). Glavni gradovi kao turističke destinacije. Menadžment u hotelijerstvu i turizmu, 4(1), 21-30.

Milićević, S., Štetić, S. (2017). Menadžment u turizmu. Vrnjačka Banja: Univerzitet u Kragujevcu, Fakultet za hotelijerstvo i turizam u Vrnjačkoj Banji.

Pavković, V., Filipović, V., Vlastelica-Bakić, T. (2015). Uloga filma kao instrumenta medijskih komunikacija u strategiji promocije turističke destinacije. Turističko poslovanje, 2015(16), 75-88. DOI:10.5937/TurPos1516075P

Pivac, T. (2016). Filmski turizam. Novi Sad: Prirodno matematički fakultet, Departmen za geografiju, turizam i hotelijerstvo. Preuzeto 17.05.2018: http://www.dgt.pmf.uns.ac.rs/download/filmskturizam240516.pdf

Roesch, S. (2009). The experiences of film location tourists. Bristol: Channel View Publications.

SEEBTM (2010). Film in Serbia/ Snimajte u Srbiji. Preuzeto 17.05.2018: https://www.seebtm.com/film-in-serbiasnimajte-u-srbiji/

Sylt, C. (2017). Harry Potter Tour Conjures Up \$435 Million Of Revenue For Time Warner. Preuzeto 17.05.2018: https://www.forbes.com/sites/csylt/2017/12/06/harry-potter-tour-conjures-up-435-million-of-revenuefor-time-warner/

Tanasić, B. (2015). Uloga igranog filma u promociji turističke destinacije, International Scientific Conference of IT and Business-Related Research: Tourism Hospitality SYNTHESIS 2015. DOI:10.15308/Synthesis2015-491-493

Tanskanen, T. (2012). Film Tourism: Study on How Films Can Be Used to Promote Tourism. Laurea Kerava: Laure University of Applied Sciences.

The Guardian (2004). Che leads the holiday revolution in South America. Preuzeto 17.05.2018: https://www. theguardian.com/travel/2004/sep/19/travelnews.observerescapesection1

UNWTO (2017). Survey on Big Data and Cultural Tourism. Preuzeto 17.08.2018: http://www2.unwto.org/ru/ node/49474

\title{
THE IMPACT OF THE FILM INDUSTRY ON TOURIST DESTINATIONS
}

\begin{abstract}
:
As a result of changes in the environment, specific tourism forms appear on the tourism market, such as film tourism. The aim of the paper is to illustrate the impact that the film industry has on tourist destinations and to define what the film tourism destination is. Film tourism can appear in a certain place as a result of showing the destination in a film or series, due to filming at that location, because of the existence of attractions significant for the film industry such as amusement parks, festivals, etc. In order to define the impact of the film industry on the destination, it should be pointed out that the destination is difficult to define and that its space is not always defined by administrative boundaries. The borders of the tourist destination are usually determined by the wishes of tourists, and therefore motives of film-induced tourists must be examined.
\end{abstract}

Keywords:

film tourism, film, tourist destination, film festivals, tourists 